\title{
Editorial: Biomass, Bioenergy and Biofuels for Circular Bioeconomy
}

\author{
Nídia S. Caetano ${ }^{1}$, Suyun $\mathrm{Xu}^{2}$, Jeyakumar Rajesh Banu ${ }^{3}$, Rajesh K. Sani ${ }^{4,5}$ and \\ Obulisamy Parthiba Karthikeyan ${ }^{6,7,8 *}$
}

\begin{abstract}
${ }^{1}$ Department of Chemical Engineering, Instituto Superior de Engenharia do Porto (ISEP), Porto, Portugal, ${ }^{2}$ School of Environment and Architecture, University of Shanghai for Science and Technology, Shanghai, China, ${ }^{3}$ Department of Life Sciences, Central University of Tamil Nadu, Thiruvarur, India, ${ }^{4}$ Department of Chemical and Biological Engineering, South Dakota School of Mines and Technology, Rapid City, SD, United States, ${ }^{5}$ Department of Chemistry, Biology, and Health Sciences, South Dakota School of Mines and Technology, Rapid City, SD, United States, ${ }^{6}$ Department of Engineering, College of Technology, University of Houston, Houston, TX, United States, ${ }^{7}$ Institute of Bioresource and Agriculture, Hong Kong Baptist University, Hong Kong SAR, China, ${ }^{8}$ Department of Civil and Environmental Engineering, South Dakota School of Mines and Technology, Rapid City, SD, United States
\end{abstract}

Keywords: organic biomass, value chain addition, nutrient recycling, biotechnology, circular economy

Editorial on the Research Topic

Biomass, Bioenergy and Biofuels for Circular Bioeconomy

\section{EDITORIAL NOTE}

The huge demand for energy and products, mostly based on fossil fuels, have caused severe environmental impacts, that are based on pollution, greenhouse gas (GHG) emissions, and finally of climate changes. While energy can be supplied from different renewable sources, such as solar, wind or hydro energy, they are intrinsically impossible or hard to control, or dependent on climatic conditions that are becoming more and more unpredictable. In this context, biomass has come, once more, as one of the potential solutions to add to the renewable energy mix.

The use of biomass as a feedstock for valuable chemicals and biofuels, contributes to more efficient

Edited and reviewed by: Uwe Schröder,

University of Greifswald, Germany

*Correspondence:

Obulisamy Parthiba Karthikeyan opkens@gmail.com

Specialty section:

This article was submitted to

Bioenergy and Biofuels,

a section of the journal Frontiers in Energy Research

Received: 08 January 2022 Accepted: 20 January 2022

Published: 14 February 2022

Citation:

Caetano NS, Xu S, Banu JR, Sani RK and Karthikeyan OP (2022) Editorial: Biomass, Bioenergy and Biofuels for

Circular Bioeconomy.

Front. Energy Res. 10:851047. doi: 10.3389/fenrg.2022.851047 use of biomass, converting the Fossil-Based Economy (FBE) into a Circular Bioeconomy (CBE) (Figure 1: Conceptual diagram). To achieve CBE, efficient resource strategies as well as efficient and sustainable green technologies must be developed. Also, to maintain the value of product carbon, waste/wastewater, greenhouse gas emissions, and damage to the ecosystems by disposal and natural resources depletion should be reduced. This chain of processes frames the new CBE, aimed at attaining a net zero-carbon society. It is currently in the early stage of conceptualization and practice. The CBE mainly relies on biomass carbon (i.e., any biodegradable organic sources) as a building block, while social, economic, and environmental components are the key drivers.

Within the framework of CBE development, as a first step the biomass production, process developments and reutilization strategies need to be well understood to meet the global supply chain and demand. It is then needed to perform the techno-economic (TE) and life cycle assessment (LCA) for each process development and integration, which should also consider the wastewater and greenhouse gas repurposing strategies within the biomass, bioenergy and biofuel production aspect of the CBE framework. Finally, the standard and policies could be proposed for successful demonstration and global realization. Considering the growing population and demand for dwindling resources, it is very important to adapt the CBE frameworks as early as possible. The lack of available information, resources and research and development are bottlenecks. Therefore, in this Research Topic different strategies of Biomass Conversion to Biofuels and Bioenergy within the $\mathrm{CBE}$ framework have been presented and proposed. Due to covid impacts, we were able to get only three articles for this collection as summarized below. 


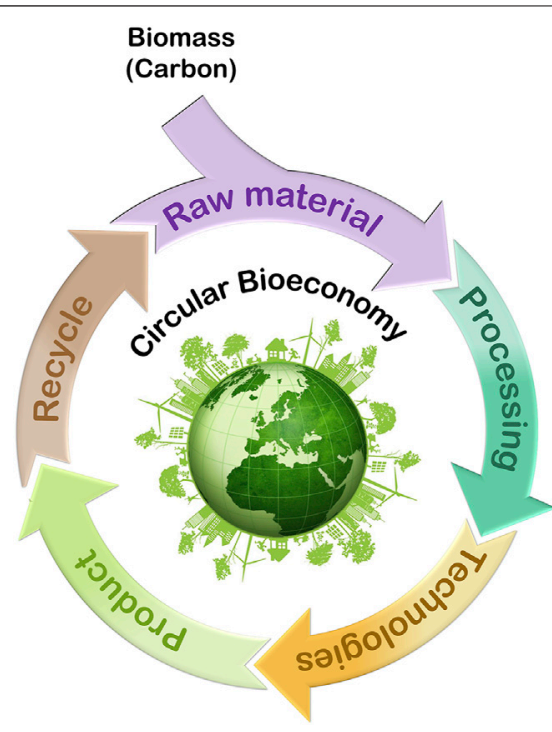

FIGURE 1 | Use of biomass within the circular bioeconomy concept.

In the conventional linear (fossil based) economy, agricultural wastes can be considered a problem that causes an environmental burden. To this respect, Khamwichit et al. proposed the use of coconut juice residues (CJRs) as the feedstock to produce bacterial cellulose (BC), that could then be acetylated to synthesize biocellulose acetate (bio-CA) membranes. These membranes could then be used to efficiently remove $\mathrm{CO}_{2}$ from biogas produced from biowaste anaerobic digestion, yielding biomethane (bio$\mathrm{CH}_{4}$ ), a renewable fuel, and $\mathrm{CO}_{2}$. Further developing this value chain, $\mathrm{CO}_{2}$ could be used for syngas production, separation processes (supercritical $\mathrm{CO}_{2}$ separation), microalgae cultivation, among other processes. This chain of processes allows further production of biofuels (biodiesel and/or bioethanol) that could be used to replace fossil fuels. This work demonstrated the possibility of achieving a zero-waste environment if the agricultural residues were used in the synthesis of high-value CA membranes for biogas purification in energy production.

Another common practice to reduce the volume of agricultural wastes is crop residue burning. This procedure is on the origin of incidents of air pollution, greenhouse gases emissions and radiation imbalance, with high public health concerns, contributing to declining organic matter in oil and soil productivity. Venkatramanan et al. estimated the crop residue burning and corresponding emissions, "aiming to recommend interventions in crop residue management and to propose a crop residue management-bioeconomy model incorporating strategies to sustainably manage the crop residues through interventions that enable waste valorization, food and nutritional security, farmers' livelihood and sustainable agricultural production system". The study was focused on North-western India, demonstrating its efforts and policies as examples for other agricultural regions having similar environmental constraints. In this study, Venkatramanan et al. concluded that crop residue management (CRM) requires a conversion from the traditional to the bioeconomy zone of CRM, with interventions aiming at the sustainability of the agroecosystem. Their bioeconomy model is a strategy based on four pillars: 1) smart agriculture practices; 2) waste bioeconomy involving aspirational principles of bioeconomy; 3) capacity building of stakeholders; and 4) proactive government policy. This new sustainable bioeconomy approach of crop residue management contributes to sustainable development as it provides alternatives to reduce crop residue burning, increase farmers' livelihood and decarbonize agricultural production.

Lipase has demonstrated excellent characteristics, selectively catalysing bio-oils and fats to biodiesel. However, designing a costeffective lipase-based biodiesel production process heavily depends on the possibility of reusing the enzymes for several times without significant loss of activity. One of the methods used to improve lipase reusability is the immobilization via adsorption-crosslinking as proposed by Nuraliyah et al. To this purpose, amino groups are needed to increase the lipase-support interaction, while contributing to increase lipase performance. Nuraliyah et al. tested the addition of amino groups on Aspergillus niger lipase immobilized on a macroporous nonionic resin (XAD-7HP) and on a macroporous anionic resin (MP-64). Chitosan, a polysaccharide naturally occurring in the crustacean exoskeleton, was used to coat the resin, being the source of amino groups. The Authors demonstrated that lipase loading and activity increased after the addition of functional amino groups from chitosan, when compared to those without chitosan coating, with good results needing further improvements to be implemented at a larger scale. Furthermore, they demonstrated the possibility of chitin shells of shrimp and other crustaceans waste valorization in the improved immobilization of lipases to be used in biodiesel production.

In summary, it is very important to adapt the CBE frameworks as early as possible to meet the future requirements of food, feed, and energy supply. The lack of available information, resources and research and development are bottlenecks to promote $\mathrm{CBE}$ concepts. Further understanding is also required to better integrate the Biomass, Bioenergy and Biofuels supply/demand and develop new policies to support the CBE frameworks.

\section{AUTHOR CONTRIBUTIONS}

NC and OPK wrote this editorial note. SX, JRB, and RS edited the final text. All coauthors approved this final version.

Conflict of Interest: The authors declare that the research was conducted in the absence of any commercial or financial relationships that could be construed as a potential conflict of interest.

Publisher's Note: All claims expressed in this article are solely those of the authors and do not necessarily represent those of their affiliated organizations, or those of the publisher, the editors and the reviewers. Any product that may be evaluated in this article, or claim that may be made by its manufacturer, is not guaranteed or endorsed by the publisher.

Copyright (C) 2022 Caetano, Xu, Banu, Sani and Karthikeyan. This is an open-access article distributed under the terms of the Creative Commons Attribution License (CC $B Y)$. The use, distribution or reproduction in other forums is permitted, provided the original author(s) and the copyright owner(s) are credited and that the original publication in this journal is cited, in accordance with accepted academic practice. No use, distribution or reproduction is permitted which does not comply with these terms. 